\title{
AVAliaçÃo de PARÂMETROS INDICADORES DE POLUIÇÃo POR EFLUENTE LÍQUIDO DE UM ATERRO SANITÁRIO
}

\author{
EVALUATION OF INDICATIVE PARAMETERS OF POLLUTION FOR LIQUID \\ EFFLUENT OF A SANITARY LANDFILL
}

\begin{abstract}
SELENE DE OLIVEIRA
Engenheira Agrícola (UFLA - Lavras/MG)

Mestre e Doutora em Agronomia/Energia na Agricultura (UNESP/FCA - Botucatu/SP), Consultora técnica especializada em gerenciamento de resíduos sólidos urbanos
\end{abstract}

ANTENOR PASQUAL

Prof. Dr. do Departamento de Recursos Naturais - FCA/UNESP - Botucatu/SP

Recebido: 12/03/04 Aceito: 14/07/04

\section{RESUMO}

O presente trabalho consistiu em determinar alguns parâmetros, químicos (metais pesados e $\mathrm{DQO}$ ) e físico-químico $(\mathrm{pH})$, indicadores de poluição/contaminação do efluente líquido do aterro sanitário municipal de Botucatu/SP, visando a avaliação da qualidade das águas subterrâneas do Aqüífero Botucatu. Os resultados obtidos na determinação dos parâmetros indicam poluição ambiental por metais pesados: cádmio, chumbo, cromo, níquel e zinco. Conseqüentemente, contaminação do lençol freático por cádmio e chumbo; da solução do solo por cádmio, chumbo e cromo; e da água superficial por níquel. Também, foi realizada uma estimativa de produção do efluente líquido para registrar a necessidade de redimensionamento dos drenos horizontais, observando a necessidade de priorizar estudos que controlem os processos construtivos e operacionais de aterros sanitários eficientes e de baixo custo.

PALAVRAS-CHAVE: Resíduos sólidos urbanos, metais pesados, lixiviado, águas subterrâneas.

\begin{abstract}
The present work consisted in to determine some parameters, chemical (heavy metals and COD) and physiochemical $(p H)$, pollution/ contamination indicative of the liquid effluent of the municipal sanitary landfill of Botucatu/SP, seeking the evaluation of the quality of groundwater of the Botucatu Aquifer. The results obtained in the determination of the parameters indicate environmental pollution of the heavy metals: cadmium, lead, chromium, nickel and zinc. Consequently, contamination of the water table for cadmium and lead; of the solution of soil for cadmium, lead, and chromium; and of the surface water for nickel. Also, an estimate of production of the liquid effluent was accomplished to register the need of new dimensioning of the horizontal drains, observing the need to prioritize studies to control the constructive and operational processes of efficient sanitary landfill and of low cost.
\end{abstract}

KEYWORDS: Municipal solid waste, heavy metals, leachate, groundwater.

\section{INTRODUÇÃO}

A população mundial supera os 6 bilhōes de pessoas. O Brasil está com uma população em torno de 174 milhões de habitantes, onde a questão dos resíduos sólidos urbanos (RSU) é preocupante, cerca de 242 mil toneladas de RSU são produzidas diariamente. A produção per capita de resíduos domésticos em áreas urbanas, no país, é em torno de $0,5 \mathrm{~kg}$ a $1,0 \mathrm{~kg}$ por dia, dependendo do porte da cidade (IPT, 2000).

O gerenciamento dos RSU não tem um manejo seguro e nem um efetivo fluxo, pois existem muitos impactos sobre a saúde pública e o meio ambiente. Em levantamento realizado pelo IBGE, a si- tuação dos municípios brasileiros referentes à disposição final dos RSU, era a seguinte: $76 \%$ na forma de lixão (dispostos a céu aberto), $13 \%$ em lixão controlado (aterrado) e $10 \%$ em aterro sanitário, $0,9 \%$ usina de compostagem e $0,1 \%$ usina de incineração (IPT, 2000).

Com relação às águas subterrâneas, no Estado de São Paulo, estima-se que $60,5 \%$ dos núcleos urbanos são servidos exclusivamente $(45,5 \%)$ ou parcialmente $(15,1 \%)$ por fontes de águas subterrâneas. Em termos de circulação de água subterrânea o Estado pode ser dividido em unidades hidroestratigráficas, por dois grandes grupos: aqüífero sedimentar, onde a permeabilidade ocorre por porosidade granular, ocupando dois ter- ços da área total do Estado (representado pelos sistemas aqüíferos Tubarão, Botucatu e Bauru e pelos aqüíferos Furnas, Taubaté, São Paulo e Coberturas Cenozóicas); e aqüífero fissurado, cuja permeabilidade se dá por descontinuidades rúpteis, é composto pelo sistema aqǘfero Cristalino e sistema aqüífero Serra Geral (IG, 1997).

A disposição incorreta ou o manuseio indevido de resíduos sólidos estão gerando ou podem gerar sérios problemas para o ambiente, inclusive provocando grande impacto nas águas subterrâneas. Aterros sanitários bem construídos (impermeabilizados e com drenos de coleta de lixiviados), operados com eficiência (com cobertura de solo ao final de cada 
período de serviço) e em localização correta (onde a vulnerabilidade do aquífero subjacente não tenha índices altos) são alternativas seguras para muitos resíduos, mas não para todos.

Vários estudos de poluição das águas subterrâneas mostram que todo lixão provoca algum tipo de poluição nas mesmas; desta forma, é de se presumir que também muitos aterros sanitários, mal construídos, poderão estar alterando a qualidade dos aquíferos. Assim, preocupaçôes como a contaminação do solo e dos recursos hídricos, das plantas, dos animais e do homem, decorrente da presença de elementos metálicos provenientes da inadequada disposição de resíduos sólidos, conduzem pesquisadores a direcionar seus objetivos de pesquisa a estes problemas.

O presente trabalho teve como objetivo a monitoração do líquido efluente (chorume) do aterro sanitário de Botucatu/SP; com determinação dos parâmetros: metais pesados (cádmio, chumbo, cromo, níquel e zinco), DQO e $\mathrm{pH}$. Justifica-se este monitoramento visto que o município de Botucatu está inserido em área de recarga do sistema Aqüífero Botucatu, e o local do depósito de resíduos situa-se na sub-bacia hidrográfica do Ribeirão do Pinheiro, onde este é afluente do Rio Pardo, que abastece parte da região.

\section{MATERIAL E MÉTODOS}

O aterro sanitário em estudo está localizado no município de Botucatu/SP, à Rodovia Intermunicipal Eduardo Zucari $\mathrm{km} 2$,5; distanciando $14 \mathrm{~km}$ do centro urbano; com uma área total de $121.387,2 \mathrm{~m}^{2}$; altitude média de $825 \mathrm{~m}$, nas coordenadas $22^{\circ} 56^{\prime} 54,0$ "latitude Sul e 48 $29^{\circ} 54,7^{\prime}$ " longitude Oeste de Greenwich, verificadas pelo aparelho GPS II (Garmin).

Quanto aos recursos hídricos, o município de Botucatu localiza-se na Bacia Hidrográfica Tietê Médio Superior, drenada pela Bacia do Rio Tietê ao norte, e do Rio Pardo ao sul, tendo este como afluente (margem direita) o Ribeirão do Pinheiro, onde em sua sub-bacia hidrográfica, de $2^{\underline{a}}$ ordem, está localizada a área do aterro sanitário, conforme pode ser verificado pelas cartas planialtimétricas do Plano Cartográfico do IBGE, escala 1:50000 de 1969, atualizados pela imagem do satélite Landsat ${ }^{\mathrm{TM}}$, escala 1:50000 de 1997, Figura 1.

Os principais tipos de solos ocorrentes no município são: Latossolo

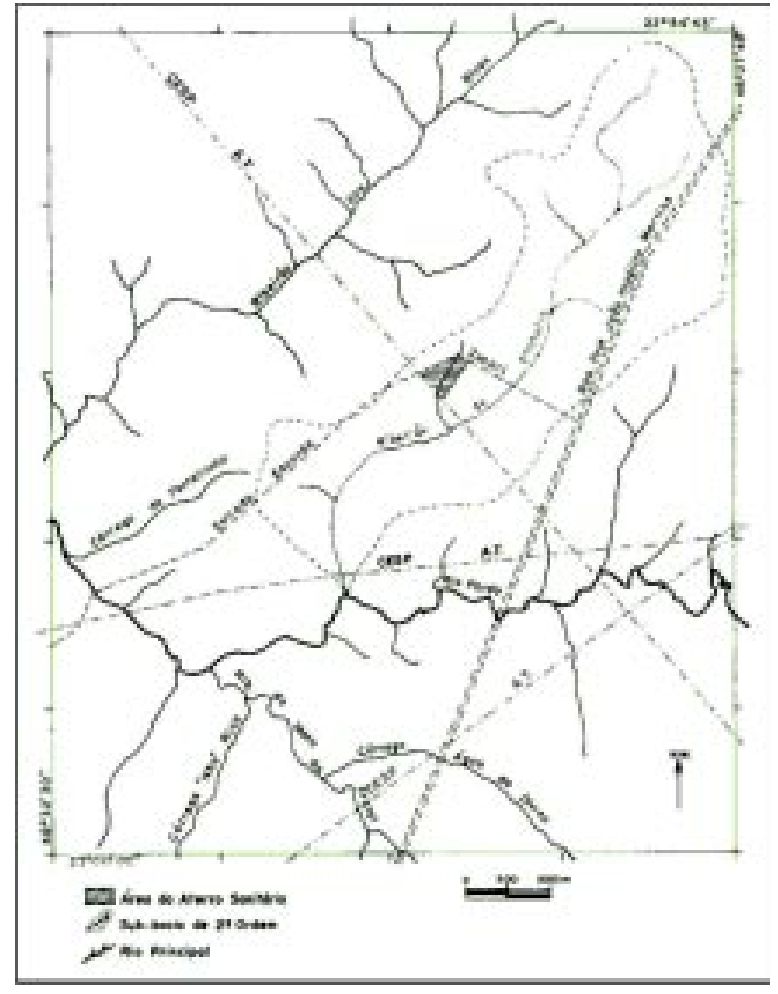

Figura I - Sub-bacia hidrográfica do Ribeirão do Pinheiro

Vermelho Escuro, Latossolo Vermelho Amarelo textura média (onde está localizado o aterro sanitário), Latossolo Roxo, Areia Quartzosa podzólica e Areia Quartzosa latossólica, Podzólico Vermelho Amarelo, Solos Litólicos, Solos Hidromórficos. No município encontrase a "Cuesta de Botucatu" que é uma forma de relevo existente dentro de um planalto (Planalto Ocidental), a parte da frente ("front") a leste, apresenta uma grande declividade, em forma de escarpa (onde se localiza o Aqüífero Botucatu), enquanto o lado oposto (reverso) a oeste, é muito maior, mas apresenta uma declividade menor; portanto, o relevo compreende três formas: frente da Cuesta, topo da Cuesta e reverso da Cuesta.

O município de Botucatu possui $26 \%\left(395,6 \mathrm{~km}^{2}\right)$ de sua área territorial inserida dentro dos limites da APA (Área de Proteção Ambiental) de Corumbataí perímetro Botucatu, criada pelo Decreto Estadual no 20.960 de 08/06/83.

A população de Botucatu com aproximadamente 110 mil habitantes produz, em média 80 toneladas de RSU por dia, representando uma produção "per capita" de $0,70 \mathrm{~kg} / \mathrm{hab}$. dia. A média brasileira para cidades de pequeno/médio porte está em torno de $0,5 \mathrm{~kg} / \mathrm{hab}$.dia, porém existe uma variação deste valor considerando o nível de renda da populaçãa. O consumo de material orgânico em comunidades de poder aquisitivo médio/baixo é maior, pois os costumes e hábitos da mesma são mais rústicos que os demais, observando a veracidade da questão: menor poder aquisitivo $\rightarrow$ maior geração de resíduos orgânicos.

A composição gravimétrica, média, dos RSU de Botucatu, e o grau de biodegrabilidade dos mesmos são apresentados no Tabela 1(Oliveira et al., 1999).

\section{MÉTODOS}

A estimativa de produção do efluente líquido foi feita pelo método do balanço hídrico, baseada no balanço hídrico normal conforme Rolim et al. (1998). Cabe ressaltar que estes cálculos foram realizados para registrar a necessidade de redimensionamento dos drenos para melhor funcionamento do aterro de Botucatu.

As condições meteorológicas foram verificadas na estação meteorológica do Departamento de Recursos Naturais da FCA/UNESP, distanciada $16 \mathrm{~km}$ do local do aterro sanitário. $\mathrm{O}$ valor mensal de vazão do líquido percolado a ser gerado no aterro sanitário foi calculado através 
da equação: $\mathrm{Q}_{\mathrm{M}}=\left(\right.$ PER. $\left.\mathrm{A}_{\mathrm{CONT}}\right) / 2592000$. Onde: $\mathrm{Q}_{\mathrm{M}}=$ vazão mensal de líquido percolado $(\mathrm{L} / \mathrm{s}) ; \mathrm{PER}=$ altura mensal percolada $(\mathrm{mm}) ; \mathrm{A}_{\mathrm{CONT}}=$ área de contribuição da seção considerada $\left(\mathrm{m}^{2}\right)$, conforme Rocca et al. (1993).

A vazão mensal de líquido percolado $\left(Q_{M}\right)$ é calculada para o dimensionamento do sistema de drenos do efluente percolado, aplicando equaçōes da Hidráulica, cujos cálculos embora importantes, não são objeto do presente trabalho.

O experimento de campo foi realizado com amostragens dos efluentes líquidos em locais estratégicos: na base do depósito de resíduos (A), na lagoa de acumulação (L) e na área livre abaixo do aterro (E e P), como mostra a Figura 2.

Foram utilizados 5 extratores de solução do solo, com comprimento de $75 \mathrm{~cm}$, construídos com tubos de PVC de $13 \mathrm{~mm}(1 / 2$ ") e tampão, cápsulas de porcelana para tensiômetros, tubos de nylon de $3 \mathrm{~mm}$ de diâmetro interno, e seringa de $10 \mathrm{ml}$, para coleta do líquido.

Os extratores foram instalados abaixo do depósito de resíduos, distanciados de 20 em $20 \mathrm{~m}$, com profundidade variavel, descrita a seguir: $\mathrm{E}_{1}=72,70 \mathrm{~cm}$; $\mathrm{E}_{2}=72,10 \mathrm{~cm} ; \mathrm{E}_{3}=70,35 \mathrm{~cm}$; $\mathrm{E}_{4}=72,15 \mathrm{~cm} ; \mathrm{E}_{5}=71,85 \mathrm{~cm}$ (Figura 2).

Foram utilizados, também, 3 piezômetros, com comprimentos diferentes, construídos com tubos de PVC de $102 \mathrm{~mm}$ (4"), nos quais foram perfurados (20 cm do seu comprimento, da extremidade inferior e em todo seu diâmetro) e a extremidade inferior foi tampada.

Os comprimentos dos piezômetros são: $\mathrm{P}=9 \mathrm{~m}$ (testemunha), $\mathrm{P}_{1}=7 \mathrm{meP}_{2}=4 \mathrm{~m}$, a diferença do comprimento foi devido à profundidade do lençol freático. $\mathrm{O}$ piezômetro testemunha $(\mathrm{P})$ foi instalado a montante do depósito de resíduos e os demais foram instalados a jusante do depósito de resíduos.

O monitoramento de coletas das amostras foi realizado de $45 \mathrm{em} 45$ dias (nos aparelhos) e de 90 em 90 dias (na lagoa e base do aterro), nos meses de maio/2000 a janeiro/2001. As amostras do líquido efluente foram coletadas conforme CETESB (1987).

Existe uma nascente do Ribeirão do Pinheiro que passa pela área do aterro, onde a mesma foi drenada com tubos fechados. Porém, fora da área do aterro a nascente é observada (distanciada $20 \mathrm{~m}$ da cerca que limita o terreno), neste local foi realizada coleta da água superficial.

Foram realizadas, também, coletas de amostras do solo na área livre abaixo

Tabela I - Características físicas, média, dos RSU de Botucatu - SP

\begin{tabular}{ccc}
\hline Componentes & Grau de biodegrabilidade & Média (\% em peso) \\
\hline Material orgânico & Facilmente degradável & 74,11 \\
Papel/papelão & Moderadamente degradável & 7,61 \\
Metal & Não degradável & 3,86 \\
Plástico & Não degradável & 8,41 \\
Vidro & Não degradável & 1,99 \\
Outros & Não degradável & 4,02 \\
\hline
\end{tabular}

Fonte: Oliveira et al. (1999).

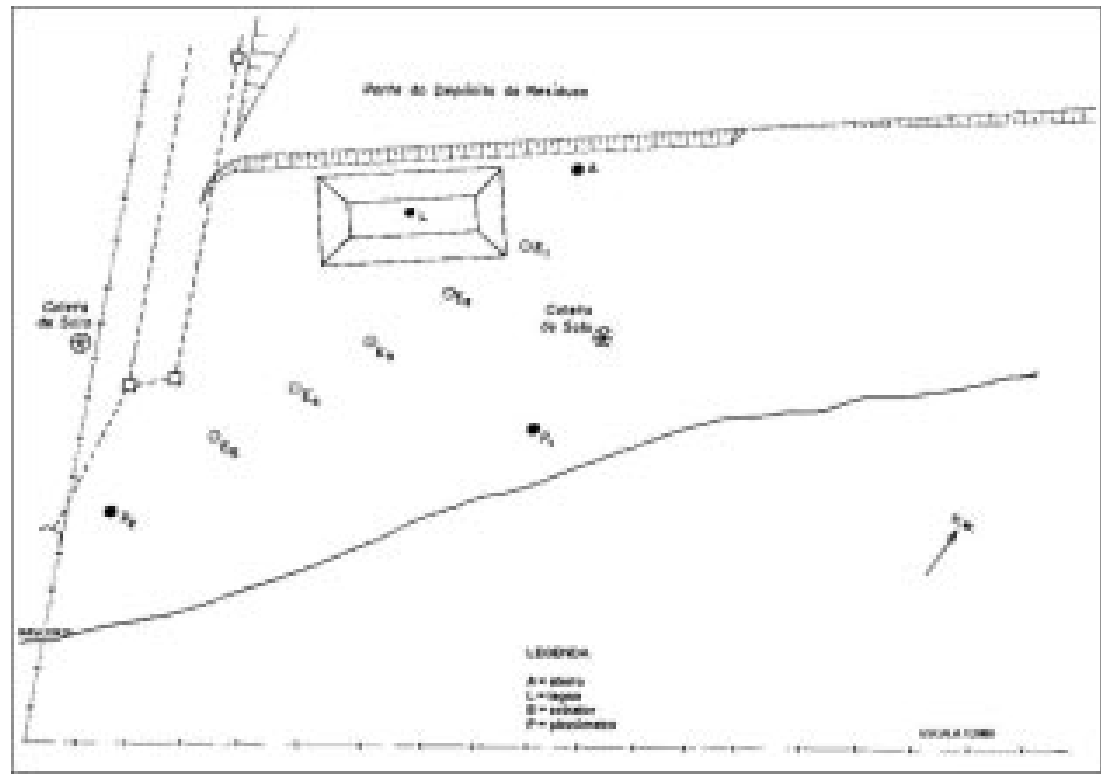

Figura 2 - Planta da localização dos pontos de amostragem do efluente líquido, no aterro de Botucatu

do aterro (onde foram instalados os aparelhos) e na área fora do aterro. As amostragens foram realizadas nas profundidades de 30,60 e $80 \mathrm{~cm}$, como mostra a Figura 2.

Os métodos das determinaçôes analíticas foram baseados conforme Standard Methods (1992).

Os parâmetros determinados e os métodos utilizados para análises são apresentados na Tabela 2 .

As análises dos efluentes líquidos e água da nascente foram desenvolvidas nos laboratórios da UNESP/Botucatu: as análises dos metais pesados foram realizadas pelo CEAQUIM/Departamento de Química e Bioquímica do IB, as análises de $\mathrm{pH}$ e DQO foram realizadas pelo laboratório de Poluição Ambiental/FCA e as análises granulométricas do solo pelo laboratório de Física do Solo/Departamento de Recursos Naturais da FCA.
As determinações de $\mathrm{Hg}$ foram realizadas no Espectrofotômetro de chama de absorção com geração de vapor a frio Mod. AA Perkin Elmer Analyst 300. E as determinaçōes de $\mathrm{Cd}, \mathrm{Pb}, \mathrm{Cr}$ total, Ni e Zn foram realizadas no Espectrofotômetro de chama de absorção Mod. Shimadzu AA 6800 .

As determinações do $\mathrm{pH}$ foram realizadas pelo aparelho $\mathrm{pHmetro}$ Digital/ Gehaka Mod. PG 1000. A DQO foi determinada pelo aparelho AquaColorPolicontrol/Polilab Mod. ACC.DQO.

O método de análise granulométrica do solo foi baseado na Norma NB 32/77 da ABNT. Utilizando: balança de precisão Mettler/Delta Range Mod. PC 2200, dispersor Tecnac Mod. TE-147), estufa Yamato/Drying Mod. D5-62.

A metodologia estatística foi desenvolvida utilizando-se estatística descritiva e modelo de regressão linear simples. 
Tabela 2 - Parâmetros determinados e métodos utilizados para análises

\begin{tabular}{ccc}
\hline Parâmetros & Métodos & Unidades \\
\hline DQO & Colorimétrico & $\mathrm{mg} / \mathrm{L}$ \\
$\mathrm{pH}$ & Potenciométrico & -- \\
Cádmio & Absorção atômica & $\mathrm{mg} / \mathrm{L}$ \\
Chumbo & Absorção atômica & $\mathrm{mg} / \mathrm{L}$ \\
Crômio total & Absorção atômica & $\mathrm{mg} / \mathrm{L}$ \\
Mercúrio & Absorção atômica & $\mathrm{mg} / \mathrm{L}$ \\
Níquel & Absorção atômica & $\mathrm{mg} / \mathrm{L}$ \\
Zinco & Absorção atômica & $\mathrm{mg} / \mathrm{L}$ \\
\hline
\end{tabular}

Para o estudo das concentrações de metais pesados foi utilizado o modelo de regressão linear simples e para os demais parâmetros (ambientais) analisados foi utilizada estatística descritiva.

O modelo de regressão linear simples é o seguinte:

$Y_{i j}=\alpha_{i j}+\beta_{i j} X_{i j}+\epsilon_{i j}$ onde:

$\mathrm{i}=$ i-ésima observação $(\mathrm{i}=1,2,3,4,5)$;

$\mathrm{j}=\mathrm{j}$-ésimo metal pesado $(\mathrm{j}=\mathrm{Cd}, \mathrm{Pb}, \mathrm{Cr}$, Ni e Zn);

$\mathrm{Y}_{\mathrm{ij}}=$ concentração acumulada $(\mathrm{mg} / \mathrm{L}) \mathrm{do}$ j-ésimo metal pesado da i-ésima observação;

$\alpha_{\mathrm{ij}}=$ constante populacional referente ao intercepto da equação de reta, da i-ésima observação e j-ésimo metal pesado;

$\beta_{\mathrm{ij}}=$ constante populacional referente à inclinação da equação de reta, da i-ésima observação e j-ésimo metal pesado (expressa a velocidade instantânea $\left.=\mathrm{mg} / \mathrm{L} \cdot \mathrm{dia}^{-1}\right)$;

$X_{\mathrm{ij}}=$ tempo em dias da i-ésima observação e j-ésimo metal pesado;

$\epsilon_{\mathrm{ij}}=$ componente aleatório (probabilístico) do modelo da i-ésima observação e j-ésimo metal pesado.

Este modelo foi inicialmente ajustado para cada metal pesado analisado, com o objetivo de comparação dos intervalos de confiança (IC) dos coeficientes angulares $\beta_{\mathrm{i}}$. Quando existir intercepto entre os dois intervalos de confiança para $\beta$ (à $95 \%$ de confiabilidade), isto equivale a um teste de hipótese, cuja hipótese $H_{o}: \beta_{1}=\beta_{2}$ não é rejeitada, contra a hipótese alternativa $H_{2}: \beta_{1} \neq \beta_{2}$.

\section{RESULTADOS E DISCUSSÃO}

Os resultados do presente trabalho serão apresentados juntamente com a dis- cussão, para facilitar a elaboração do texto e a sua compreensão.

A estimativa de produção do efluente líquido foi efetuada pelo método do balanço hídrico, baseada no balanço hídrico normal mensal de Botucatu, no ano de 2000. As Figuras 3 e 4 mostram o resultado do balanço hídrico normal mensal e o extrato deste balanço. A Tabela 3 mostra o resultado do balanço hídrico na área do aterro sanitário.

O total da precipitação em Botucatu (ano de 2000) foi igual a 1301,8 mm, com média de $108,5 \mathrm{~mm}$; e temperatura média de $20,2^{\circ} \mathrm{C}$. O tipo de solo do local do aterro sanitário é de textura média e com $65 \%$ de areia total; seu relevo é ondulado com declividade de 2 a $5 \%$.

A vazão mensal de líquido percolado a ser gerado no aterro sanitário foi calculada através da equação:

$\mathrm{Q}_{\mathrm{M}}=\left(\mathrm{PER} \cdot \mathrm{A}_{\mathrm{CONT}}\right) / 2592000$

onde:

$\mathrm{Q}_{\mathrm{M}}=$ vazão mensal de líquido percolado (L/s);

$\mathrm{PER}=$ altura mensal percolada $(\mathrm{mm})$;

$\mathrm{A}_{\mathrm{CONT}}=$ área de contribuição da seção considerada $\left(\mathrm{m}^{2}\right)$.

Verificando a altura mensal percolada (PER) pela Tabela 3, e a área de contribuição da seção considerada $\left(\mathrm{A}_{\mathrm{CONT}}\right)$ pelo aparelho GPS II, calculou-se a vazão mensal de líquido percolado $\left(\mathrm{Q}_{\mathrm{M}}\right)$.

Se:

$\mathrm{PER}=105,5 \mathrm{~mm}$

$\mathrm{A}_{\mathrm{CONT}}=21691,8 \mathrm{~m}^{2}$ (área onde os resíduos estão aterrados).

Então:

$Q_{M}=\frac{(105,5 \times 21691,8)}{2592000} \Rightarrow Q_{M}=0,88 \mathrm{~L} / \mathrm{s}$. 2592000

Nota-se que a geração significante de percolado existe somente nos meses de janeiro a março, e que a média da percolação (PER) é igual a 35,2 $\mathrm{mm}$ e o cálculo da vazão $\left(Q_{M}\right)$ será igual a $0,29 \mathrm{~L} / \mathrm{s}$. É recomendado utilizar o valor da percolação média dos meses de geração do percolado, pois usando o valor anual implicaria em um dimensionamento exagerado dos drenos, segundo Orth e Di Creddo (1999).

Na Tabela 4 são apresentados os resultados médios dos parâmetros determinados, e os valores máximos permissíveis pela Resolução CONAMA no 20 de 18/06/86, que classifica as águas doces, salobras e salinas do território nacional segundo seus usos preponderantes (artigos $4^{\circ} \mathrm{e}$ 21); e pela Portaria no 36 de 19/01/90 do Ministério da Saúde (MS), que estabelece o padrão de potabilidade da água destinada ao consumo humano (atualizada pela Portaria $\mathrm{n}^{\circ} 1469$ de 29/12/2000 e pela Portaria $\mathrm{n}^{\mathrm{o}} 518$ de 25/03/2004).

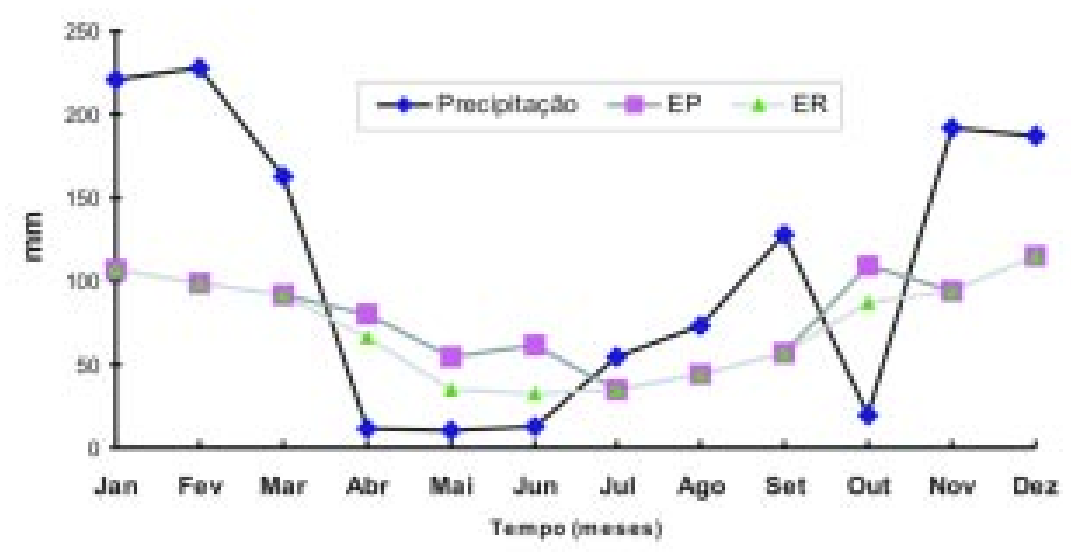

Figura 3 - Balanço hídrico normal mensal do ano 2000, de Botucatu 


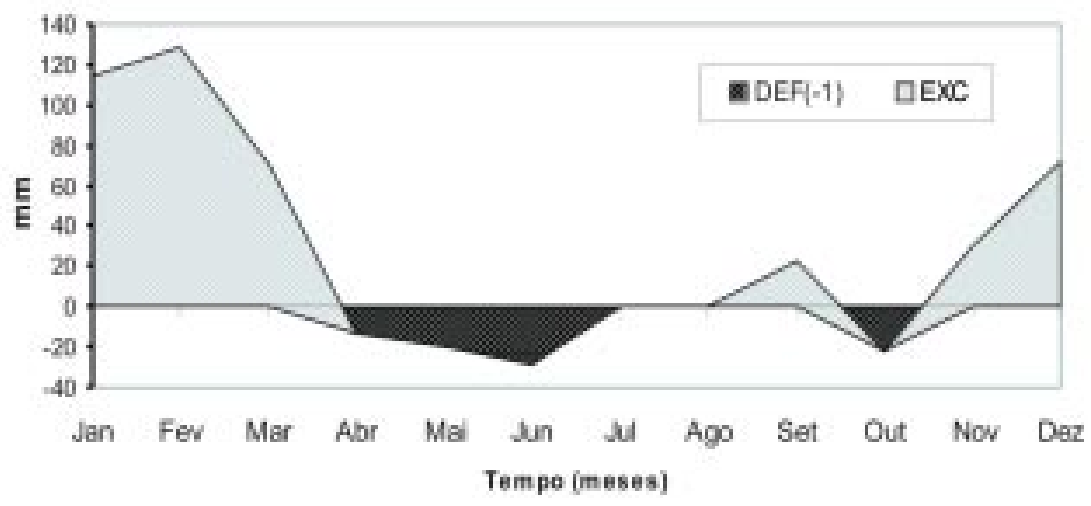

Figura 4 - Extrato do balanço hídrico normal mensal de Botucatu, ano 2000

Tabela 3 - Resultado do balanço hídrico do local do aterro de Botucatu/SP (mm). Ano 2000

\begin{tabular}{cccccccccccc}
\hline Meses & EP & $\mathrm{P}$ & $\mathrm{C}^{\prime}$ & $\mathrm{ES}$ & $\mathrm{I}$ & $(\mathrm{I}-\mathrm{EP})$ & $\mathrm{NEG}(\mathrm{I}-\mathrm{EP})$ & AS & $\Delta$ AS & ER & PER \\
\hline Janeiro & 106,7 & 220,7 & 0,34 & 75,0 & 145,7 & $+39,0$ & 0,0 & 150,0 & 0,0 & 106,7 & 39,0 \\
Fevereiro & 98,9 & 227,9 & 0,34 & 77,5 & 150,4 & $+51,5$ & 0,0 & 150,0 & 0,0 & 98,9 & 51,5 \\
Março & 92,2 & 162,4 & 0,34 & 55,2 & 107,2 & $+15,0$ & 0,0 & 150,0 & 0,0 & 92,2 & 15,0 \\
Abril & 80,0 & 12,1 & 0,17 & 2,1 & 10,0 & $-70,0$ & $-70,0$ & 93,0 & $-57,0$ & 67,0 & 0 \\
Maio & 54,3 & 10,3 & 0,17 & 1,8 & 8,5 & $-45,8$ & $-115,8$ & 68,0 & $-25,0$ & 33,5 & 0 \\
Junho & 61,6 & 12,8 & 0,17 & 2,2 & 10,6 & $-51,0$ & $-167,4$ & 48,0 & $-20,0$ & 30,6 & 0 \\
Julho & 34,4 & 55,0 & 0,17 & 9,4 & 45,6 & $+11,2$ & 0,0 & 59,2 & $+11,2$ & 34,4 & 0 \\
Agosto & 44,5 & 73,7 & 0,17 & 12,5 & 61,2 & $+16,7$ & 0,0 & 75,9 & $+16,7$ & 44,5 & 0 \\
Setembro & 56,4 & 127,9 & 0,17 & 21,7 & 106,2 & $+49,8$ & 0,0 & 125,7 & $+49,8$ & 56,4 & 0 \\
Outubro & 109,7 & 20,3 & 0,34 & 6,9 & 13,4 & $-96,3$ & $-96,3$ & 78,0 & $-47,7$ & 61,1 & 0 \\
Novembro & 93,9 & 191,9 & 0,34 & 65,3 & 126,6 & $+32,7$ & 0,0 & 110,7 & $+32,7$ & 93,9 & 0 \\
Dezembro & 115,1 & 186,8 & 0,34 & 63,5 & 123,3 & $+8,2$ & 0,0 & 118,9 & $+8,2$ & 115,1 & 0 \\
\hline Total & & & & & & & & & & & 105,5 \\
\hline
\end{tabular}

Nota: $\mathrm{EP}$ = evaporação potencial, $\mathrm{P}$ = precipitação, $\mathrm{C}^{\prime}=$ coeficiente do escoamento superficial, $\mathrm{ES}$ = escoamento superficial; $\mathrm{I}$ = infiltração. $(\mathrm{I}-\mathrm{EP})$ = diferença entre a quantidade de água infiltrada e evapotranspiração; NEG (I-EP) = perda potencial de água acumulada. $\mathrm{AS}=$ armazenamento de água no solo; $\Delta A S$ = troca de armazenamento de água no solo; $\mathrm{ER}$ = evapotranspiração real; $\mathrm{PER}=$ percolação.

Observou-se que no piezômetro testemunha $(\mathrm{P})$ não houve efluente para coleta e no piezômetro (P2) a coleta de amostras foi insuficiente. $\mathrm{Na}$ época da instalação dos piezômetros o lençol freático estava alto, porém, como o período de chuva foi escasso no decorrer do monitoramento, o nível do lençol freático abaixou e com isso não foi possível a coleta de amostras em todo o período do experimento, portanto, o piezômetro (P1) foi o representativo nas determinaçōes de metais pesados.
Nos resultados das determinaçóes dos metais pesados no piezômetro (P1) foi realizado tratamento estatístico pelo método de regressão linear simples, como mostram as Figuras 5 e 6. Para as determinaçōes de metais pesados analisados nas amostras de P1 foi realizado um ajuste para cada concentração de metal pesado, para comparação dos intervalos de confiança (IC) dos coeficientes angulares $\beta_{\mathrm{i}}$, como mostra a Tabela 5.

Observando a Tabela 5, e após o ajuste realizado, verificou-se que:
- Para o metal Zn, no intervalo de confiança $\left(\mathrm{IC}_{\alpha}\right)$, o zero não está presente; assim, o modelo utilizado será: $Y_{\mathrm{ij}}=\alpha_{\mathrm{ij}}+\beta_{\mathrm{ij}} X_{\mathrm{ij}}+\epsilon_{\mathrm{ij}}$. A Figura 5 mostra as concentraçoes acumuladasdeZnnasamostras de $\mathrm{P} 1$ ao longo do tempo de amostragem.

- Para os demais metais $(\mathrm{Cd}, \mathrm{Pb}$, $\mathrm{Cr}, \mathrm{eNi})$, no intervalo de confiança $\left(\mathrm{IC}_{\alpha}\right)$, o zero está presente; assim, o modelo utilizado será: $Y_{\mathrm{ij}}=\beta_{\mathrm{ij}} X_{\mathrm{ij}}+\in_{\mathrm{ij}}$. A Figura 6 mostra as concentraçôes de $\mathrm{Cd}, \mathrm{Pb}, \mathrm{Cr}$, e $\mathrm{Ni}$ nas amostras de P1 no tempo decorrido em dias. 
Tabela 4 - Resultados dos parâmetros determinados, e valores máximos permissíveis por lei

\begin{tabular}{|c|c|c|c|c|c|c|c|c|c|c|}
\hline \multicolumn{8}{|c|}{ Valores (mg/L) } & \multicolumn{3}{|c|}{$\mathrm{pH}$} \\
\hline Locais & DQO & $\mathrm{Cd}$ & $\mathrm{Pb}$ & $\mathrm{Cr}$ & $\mathrm{Hg}$ & $\mathrm{Ni}$ & $\mathrm{Zn}$ & Locais & Mín. & Máx. \\
\hline $\mathrm{P}$ & - & -- & -- & - & -- & -- & -- & $\mathrm{P}$ & -- & -- \\
\hline P1 - (M) & 16 & 0,026 & 0,065 & 0,028 & nd & 0,094 & 0,082 & P1 & 6,2 & 6,4 \\
\hline P1 - (DP) & 10,3 & 0,015 & 0,049 & 0,020 & - & 0,076 & 0,040 & - & - & - \\
\hline P2 - (M) & 45 & 0,013 & 0,037 & 0,019 & nd & 0,014 & 0,014 & P2 & 5,4 & 6,2 \\
\hline $\mathrm{P} 2$ - (DP) & 7,1 & 0,004 & 0,017 & 0,012 & - & 0,009 & 0,004 & - & - & - \\
\hline E1 & 25 & 0,173 & 0,114 & 0,216 & nd & 0,442 & 0,447 & E1 & & \\
\hline E2 - (M) & 19,5 & 0,232 & 0,531 & 0,151 & nd & 0,572 & 0,647 & E2 & 6,1 & 6,6 \\
\hline $\mathrm{E} 2-(\mathrm{DP})$ & 0,7 & 0,030 & 0,197 & 0,023 & - & 0,092 & 0,098 & - & - & - \\
\hline E3 & -- & -- & -- & -- & - & -- & & E3 & - & -- \\
\hline E4 & 10 & -- & -- & -- & -- & -- & -- & E4 & & \\
\hline E5 & 11 & -- & -- & -- & -- & -- & -- & E5 & & \\
\hline$v m p^{* *}$ & ** & 0,005 & 0,050 & 0,050 & - & ** & 5,0 & - & 6,5 & 8,5 \\
\hline Aterro - (M) & 3.000 & 0,053 & 0,062 & 0,037 & nd & 0,406 & 0,142 & Aterro & 8,6 & 9,1 \\
\hline Aterro - (DP) & 2291,3 & 0,019 & 0,023 & 0,016 & - & 0,261 & 0,052 & - & - & - \\
\hline Lagoa - (M) & $\cong 10.000$ & 0,035 & 0,083 & 0,025 & nd & 0,183 & 0,097 & Lagoa & 8,0 & 8,4 \\
\hline Lagoa - (DP) & 13137,1 & 0,016 & 0,074 & 0,008 & - & 0,139 & 0,045 & - & - & - \\
\hline$v m p^{* * *}$ & *** & 0,2 & 0,5 & 2,0 & - & 2,0 & 5,0 & - & 5,0 & 9,0 \\
\hline Nascente & 35 & nd & nd & 0,005 & na & 0,108 & 0,049 & Nascente & & \\
\hline$v m p^{* * *}$ & $* * *$ & 0,001 & 0,030 & 0,500 & - & 0,025 & 0,180 & - & 6,0 & 9,0 \\
\hline
\end{tabular}

Tabela 5 - Coeficientes de determinação $R^{2}$, estimativa de $\alpha$ e $\beta$ e intervalos de confiança para $\beta$, segundo concentrações dos metais pesados nas amostras de PI

\begin{tabular}{ccccc}
\hline Metal pesado & R2 (\%) & $\alpha$ (estimado & $\beta$ (estimado) & IC $(\beta)_{95 \%}$ \\
\hline $\mathrm{Zn}$ & 96,82 & 0,0939 & 0,0015 & {$[0,0010 ; 0,0020]$} \\
$\mathrm{Cd}$ & 95,94 & - & 0,0006 & {$[0,0004 ; 0,0007]$} \\
$\mathrm{Pb}$ & 98,85 & - & 0,0015 & {$[0,0013 ; 0,0017]$} \\
$\mathrm{Cr}$ & 94,46 & - & 0,0007 & {$[0,0005 ; 0,0008]$} \\
$\mathrm{Ni}$ & 96,98 & - & 0,0022 & {$[0,0017 ; 0,0027]$} \\
\hline
\end{tabular}

Observando, ainda na Tabela 5 e Figura 6, nota-se que existe intercepto entre os intervalos de confiança (b à $95 \%$ de confiabilidade) dos metais $\mathrm{Cd}$ e $\mathrm{Cr}$, ou seja, pelo teste de hipótese, $\mathrm{a}_{\mathrm{o}}: \mathrm{b}_{\mathrm{Cd}}=\mathrm{b}_{\mathrm{Cr}}$ é aceita e a $\mathrm{H}_{\mathrm{a}}: \mathrm{b}_{\mathrm{Cd}} \neq \mathrm{b}_{\mathrm{Cr}}$ rejeitada ao nível de $5 \%$ de significância, desta forma podese verificar que a velocidade instantânea $\left(\mathrm{mg} / \mathrm{L} . \mathrm{dia}^{-1}\right)$ destes metais é igual no efluente líquido. E não existe intercepto entre IC (b) ${ }_{95 \%}$ do $\mathrm{Pb}$ e Cd, ou seja, pelo teste de hipótese $\mathrm{H}_{\mathrm{o}}: \mathrm{b}_{\mathrm{Pb}}=\mathrm{b}_{\mathrm{Cd}}$ é rejeitada e $\mathrm{H}_{\mathrm{a}} \mathrm{b} \mathrm{b}_{\mathrm{Pb}} \neq \mathrm{b}_{\mathrm{Cd}}$ aceita. Também não existe intercepto entre IC (b) ${ }_{95 \%} \mathrm{~Pb}$ e $\mathrm{Cr}$, ou seja, pelo teste de hipótese $\mathrm{H}_{\mathrm{o}}: \mathrm{b}_{\mathrm{Pb}}=\mathrm{b}_{\mathrm{Cr}}$ é rejeitada e $\mathrm{H} \mathrm{H}_{\mathrm{a}} \mathrm{b}_{\mathrm{Pb}} \neq \mathrm{b}_{\mathrm{Cr}}$ aceita. Não existe intercepto entre IC (b) ${ }_{95 \%} \mathrm{~Pb}$ e $\mathrm{Ni}$, ou seja, pelo teste de hipótese $\mathrm{H}_{\mathrm{o}}: \mathrm{b}_{\mathrm{Pb}}=\mathrm{b}_{\mathrm{Ni}}$ é rejeitada e $\mathrm{H}_{\mathrm{a}}: \mathrm{b}_{\mathrm{Pb}} \neq \mathrm{b}_{\mathrm{Ni}}$ aceita ao nível de $5 \%$ de significância, onde o $\mathrm{Pb}$ e o $\mathrm{Ni}$ têm uma velocidade instantânea distinta. Portanto, os metais Cd e Cr têm um comportamento semelhante na cinética do efluente (na água subterrânea); e os metais $\mathrm{Pb}$ e Ni têm um comportamento distinto dos outros.

Ainda, com relação as amostras, da água subterrânea em P1, pode-se verificar na Tabela 4, que foram detectados os metais $\mathrm{Cd}, \mathrm{Cr}, \mathrm{Pb}$, Ni e $\mathrm{Zn}$, porém somente as concentrações de $C d$ e $P b$ estão em desacordo com os padrôes de potabilidade da água estabelecidos pela Portaria no 36/90 do Ministério da Saúde; isto pode ser atribuído ao mecanismo atenuador do solo, pois segundo Santos (1996) os mais importantes mecanismos de atenuação do Cr, Ni e Zn são os processos de adsorção e precipitação química.

$\mathrm{Na}$ coleta de amostras do efluente percolado nos extratores de solução do solo, verificou-se que nos extratores E1, 


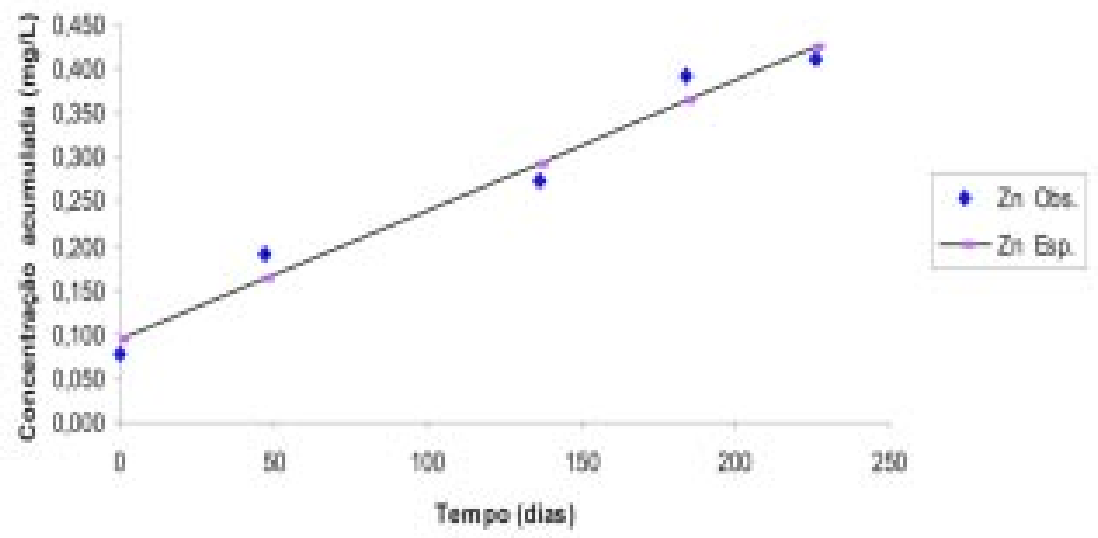

Figura 5 - Concentração de Zn nas amostras do piezômetro PI

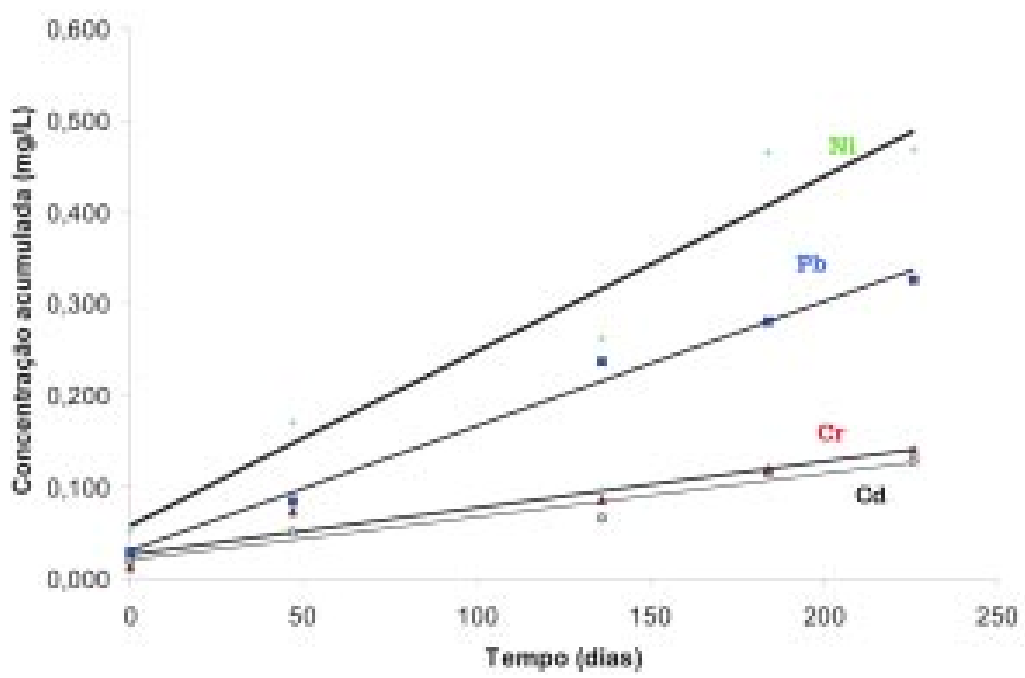

Figura 6 - Concentrações dos metais Cd, Cr, Pb e Ni nas amostras do piezômetro $P I$

E3, E4, e E5 não tiveram efluente suficiente para determinações dos metais pesados, somente no E2 foi possível coletar amostras suficientes. Portanto o extrator (E2) foi o representativo nos resultados das concentrações de metais pesados, no efluente percolado; como mostra o gráfico da Figura 7.

Com relação aos resultados das determinaçōes de metais pesados no extrator $\mathrm{E} 2$, as concentraçôes, média, de $C d, P b$, e $\mathrm{Cr}$ estão em desacordo os padrōes de potabilidade da água estabelecidos pela Portaria 36/90 do Ministério da Saúde.

Os resultados das determinaçôes de metais pesados no efluente superficial, na base do aterro (talude) e na lagoa de acumulação, são apresentados nos gráficos das Figuras 8 e 9 .
Observa-se na Tabela 4 que as concentraçōes médias dos metais pesados na base do aterro estão abaixo dos valores máximos permissíveis pela Resolução CONAMA 20/86. E as concentraçôes médias na lagoa, também estão abaixo dos padrōes estabelecidos, pela Resolução CONAMA 20/86, para efluentes a serem lançados nos corpos d'água.

A queda da concentração de $\mathrm{Ni}$, na base do aterro e lagoa, pode ser atribuída a decomposição da matéria orgânica ao longo do tempo, pois material orgânico é fonte de $\mathrm{Ni}$, e também pode ser atribuí$\mathrm{da}$ a diluiçãoo pela chuva.

Os resultados das concentrações de metais pesados na água superficial da nascente do Ribeirão do Pinheiro são observadas na Tabela 4. A concentração do metal $\mathrm{Ni}$ está acima do valor máximo permissível estabelecido pela Resolução CONAMA 20/86, para classes de águas doces; os demais metais estão abaixo deste valor.

Observando, ainda, a Tabela 4 e as Figuras 5 a 9, os metais pesados $\mathrm{Cd}, \mathrm{Pb}$, $\mathrm{Cr}$, Ni e $\mathrm{Zn}$, foram detectados, nos efluentes do aterro em estudo. Comparando as características físicas dos RSU (Tabela 1) e examinando o que foi citado por Damasceno (1996) e estimado por Castilhos Jr. (1989), verifica-se que as fontes principais dos metais pesados determinados são: material orgânico $(\mathrm{Pb}, \mathrm{Ni} \mathrm{e}$ $\mathrm{Zn})$, papel $(\mathrm{Pb})$, material metálico $(\mathrm{Cd}$, $\mathrm{Pb}, \mathrm{Ni}$ e $\mathrm{Zn}$ ), plástico (Cd e Zn), vidro $(\mathrm{Cr})$, e outros: baterias ( $\mathrm{Cd}, \mathrm{Pb}, \mathrm{Ni} \mathrm{ZZn})$, borrachas $(\mathrm{Zn})$ e tecidos $(\mathrm{Cr})$.

As Figuras 10 e 11 apresentam os resultados da $\mathrm{DQO}$ e $\mathrm{pH}$ nos pontos de amostragem no decorrer do experimento.

Os resultados das análises de DQO e pH estão representados na Tabela 4. Todas as análises de $\mathrm{pH}$ determinadas estão abaixo dos valores máximos permissíveis pela Resolução CONAMA 20/86 e pela Portaria MS 36/90. O valor máximo permissível da DQO não consta na Resolução e nem na Portaria.

Comparando a Figura 10 com a Figura 3 (balanço hídrico), verifica-se que as concentrações da DQO nas amostras de P1 variam inversamente segundo a precipitação, isto pode ser atribuído ao mecanismo de diluição pela chuva.

A variação da DQO no decorrer do tempo (maio e julho) nas amostras de E2, também pode ser atribuída ao processo de diluição pela chuva.

O aumento da DQO na lagoa pode ser atribuído ao acúmulo de efluente, pois em janeiro/01 o chorume da lagoa estava concentrado.

Observando a Figura 11 verifica-se que os valores de $\mathrm{pH}$ nas amostras do piezômetro, extrator, aterro e lagoa se mantêm, praticamente, constante.

Observando, ainda, os resultados dos valores de $\mathrm{pH}$ e DQO para base do aterro e lagoa, e comparando com os estudos de Schalch (1984): pH máximo de 9,3 e DQO entre 7000 e 35000 , as concentrações estão em conformidade com o que foi analisado para chorume puro.

A Tabela 6 apresenta uma síntese dos resultados obtidos. No piezômetro a coleta foi na água subterrânea (efluente lixiviado), no extrator de solução do solo a coleta foi do efluente percolado, na base do talude do aterro e na lagoa de acumu- 


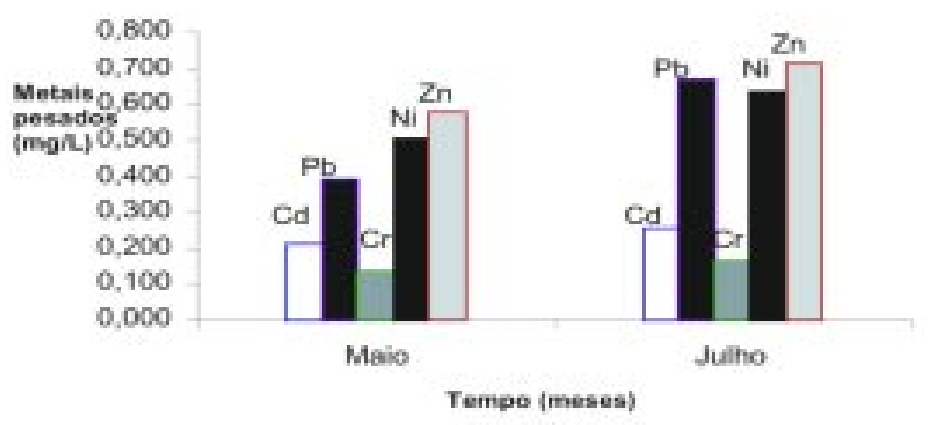

Figura 7 - Concentrações dos metais pesados nas amostras do extrator E2

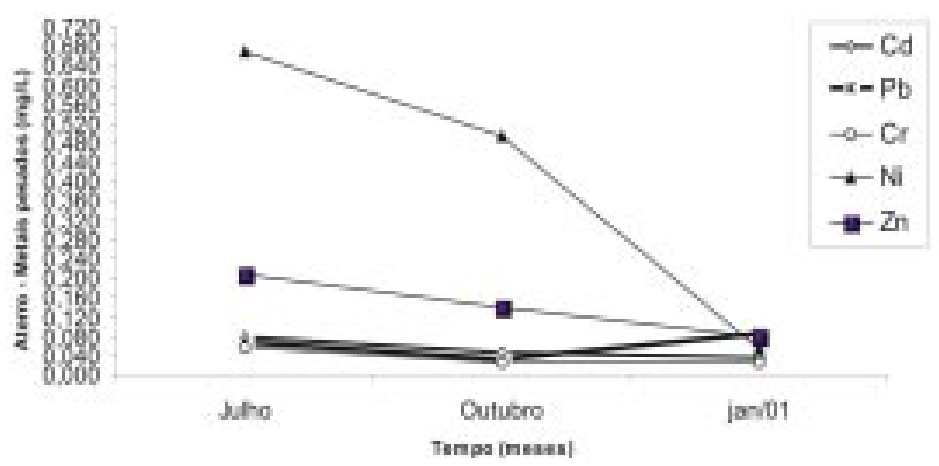

Figura 8 - Concentrações dos metais pesados na base do aterro.

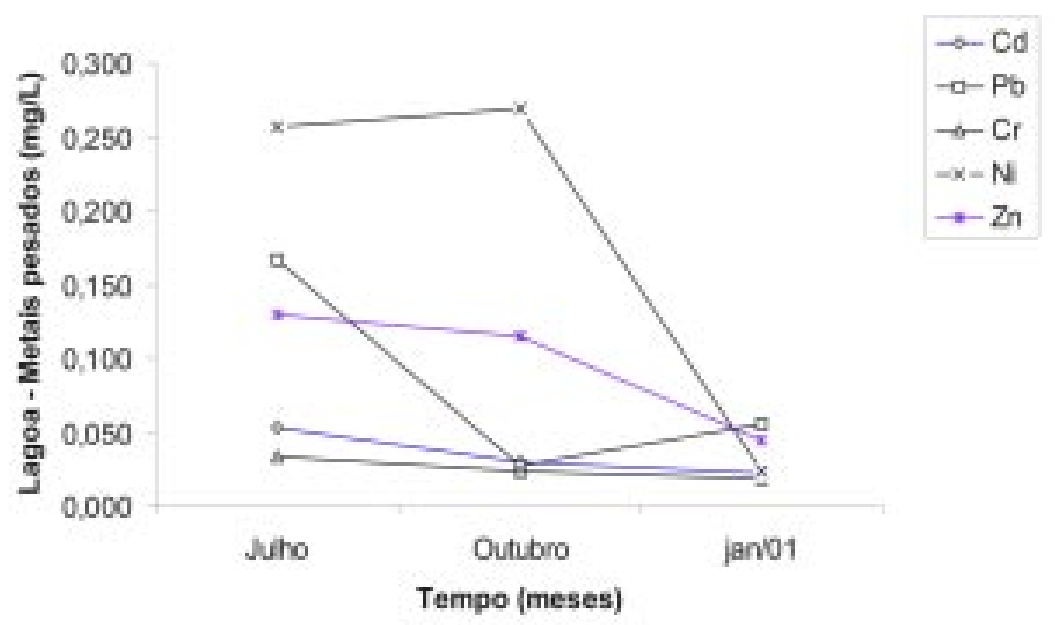

Figura 9 - Concentrações dos metais pesados na lagoa lação a coleta foi do efluente superficial e na nascente a coleta foi na águas superficial em local que a nascente aflora.

Verificando as concentraçôes dos metais pesados nos aparelhos (Tabela 6), observou-se que as concentrações dos metais no extrator são maiores que no piezômetro, esta distinção pode ser atribuída aos mecanismos de retenção dos metais no solo e/ou aos processos de lixiviação no solo. Isto está em conformidade com o que foi citado por Rocca et al. (1993): quando a água contaminada entra no solo ou aqüífero, a concentração dos poluentes decresce com o aumento da distância do fluxo.

Ainda, observando a Tabela 6, as concentraçōes dos metais na nascente, também, são menores do que o restante das amostras dos locais analisados, isto pode ser atribuído ao processo de diluição pela chuva.

As concentraçōes dos metais que estão acima dos valores máximos permissíveis pela legislação são do $\mathrm{Cd}, \mathrm{Pb}$ e $\mathrm{Cr}$ (solução do solo), $\mathrm{Cd} \mathrm{e} \mathrm{Pb}$ (água subterrânea), e Ni (nascente). Entretanto, na base do aterro e lagoa (efluente superficial) não foram constatados níveis acima do estabelecido pela legislação.

Com relação às concentrações de $\mathrm{Ni}$, observadas na Tabela 4 e 6, o valor máximo permissível (vmp) do Ni não consta na Portaria 36/90 do MS, isto pode ser atribuído ao fato de que esta Portaria estabelece o padrão de componentes inorgânicos que afetam a saúde, porém, $\mathrm{o}$ $\mathrm{Ni}$ relativamente não é tóxico e as concentraçōes a que, normalmente, o homem encontra-se exposto são aceitáveis (Damasceno, 1996). Entretanto, se estas concentrações forem comparadas com o vmp da Resolução CONAMA 20/86, verifica-se que os valores do $\mathrm{Ni}$ nestes efluentes estão acima do valor máximo permissível.

Nos resultados da análise de solo, do terreno onde foi instalado o aterro, constata-se que o mesmo é arenoso com: $65 \%$ de areia, $8 \%$ de silte e $27 \%$ de argila, com textura média. Consultando o que foi citado por Rocca et al. (1993), o teor de argila do solo escolhido para implantação de aterros deverá conter teores de argila em torno de 56 a $62 \%$, e um sistema de impermeabilização inferior, também, deverá ser construído.

A base inferior do aterro, em estudo, não foi impermeabilizada com geomembrana, mas simplesmente foi colocada uma manta asfáltica. Assim, os resultados obtidos dos parâmetros indica- 


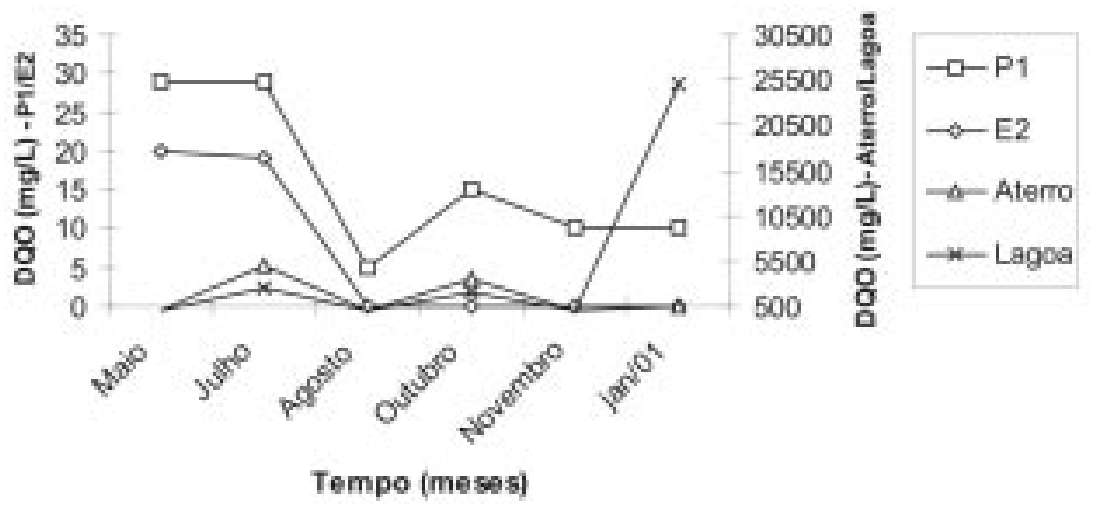

Figura 10 - Resultados da DQO nas amostras do piezômetro, extrator, base aterro e lagoa

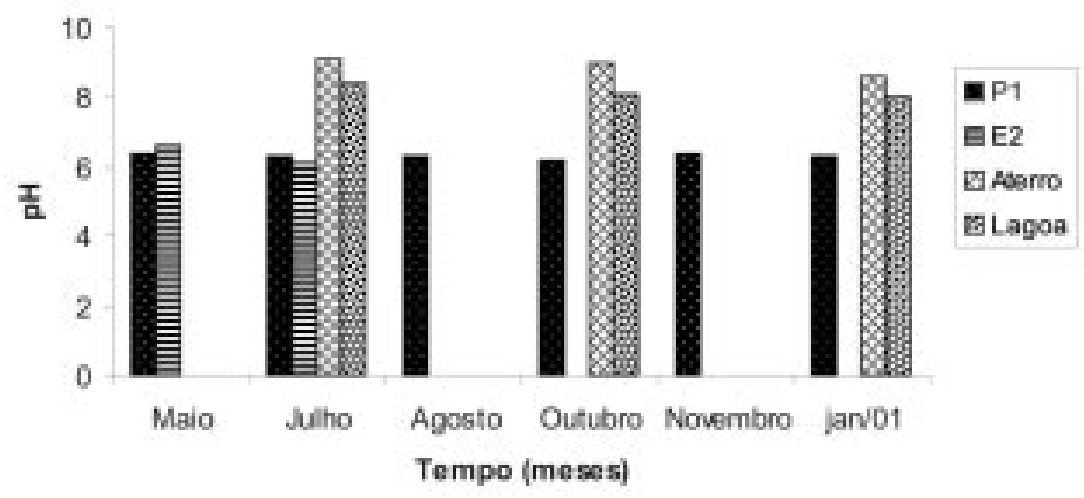

Figura I I - Resultados do pH nas amostras do piezômetro, extrator, base aterro e lagoa

Tabela 6 - Resultados dos parâmetros determinados (média, exceto para pH)

\begin{tabular}{cccccccc}
\hline Pontos de amostras & $p H^{*}$ & $D Q O$ & $C d$ & $P b$ & $C r$ & $N i$ & $Z n$ \\
\hline Piezômetro & $6,2-6,4$ & 16 & 0,026 & 0,065 & 0,028 & 0,094 & 0,082 \\
Extrator & $6,1-6,6$ & 19,5 & 0,232 & 0,531 & 0,151 & 0,572 & 0,647 \\
Base aterro & $8,6-9,1$ & 3.000 & 0,053 & 0,062 & 0,037 & 0,406 & 0,142 \\
Lagoa & $8,0-8,4$ & 10.000 & 0,035 & 0,083 & 0,025 & 0,183 & 0,097 \\
Nascente & 6,2 & 35 & nd & nd & 0,005 & 0,108 & 0,049 \\
\hline valores em mg/L & \multicolumn{5}{c}{${ }^{*}$ pH adimensional } & \multicolumn{3}{c}{ nd = não detectado }
\end{tabular}

dores de poluição, em desacordo com a legislação consultada, podem ser atribuídos à falta de uma impermeabilização adequada.

Os tipos de solos na área do aterro, segundo EMBRAPA (1988), são: Latossolo Vermelho Escuro (solos profundos, textura média a argilosa, cor vermelho escuro, bem drenados) e Latossolo Vermelho Amarelo textura média (solos profundos, bem drenados, cor vermelho, ácido de baixa fertilidade). Vale ressaltar que a região de Botucatu é uma área de recarga do Aqüífero Botucatu, e está localizada em área de proteção ambiental (APA).

\section{CONCLUSÕES}

O aterro em estudo não é considerado como um aterro sanitário quando comparado com as Normas Técnicas da ABNT. Conclui-se que o aterro pode ser considerado como uma disposição final em forma de aterro sanitário controlado.

Com o cálculo da estimativa de produção do efluente líquido, verificou-se que o dimensionamento dos drenos horizontais, para uma futura ampliação do aterro, pode ser realizado pelo valor da percolação média dos meses de geração do percolado, e não pelo valor anual.

$\mathrm{O}$ metal pesado $\mathrm{Hg}$ não foi detectado, pelo espectrofotômetro de chama de absorção com geração de vapor a frio, em nenhum dos pontos de amostragem. Conclui-se que o Hg não indica poluição/contaminação das águas subterrâneas, na época do experimento.

Os demais metais pesados $(\mathrm{Cd}, \mathrm{Pb}$, $\mathrm{Cr}, \mathrm{Ni}$, e $\mathrm{Zn}$ ) foram detectados pelo espectrofotômetro de chama de absorção. Concluí-se que estes metais indicam poluição ambiental.

As concentrações acumuladas do metal pesado $\mathrm{Zn}$ podem ser representadas pelo modelo estatístico: $Y_{\mathrm{ij}}=\alpha_{\mathrm{ij}}+\beta_{\mathrm{ij}} X_{\mathrm{ij}}+\epsilon_{\mathrm{ij} \text {. }}$ $\mathrm{E}$ as concentraçôes acumuladas dos metais pesados, $\mathrm{Cd}, \mathrm{Pb}, \mathrm{Cr}$ e $\mathrm{Ni}$ podem ser representadas pelo modelo estatístico: $Y_{\mathrm{ij}}=\beta_{\mathrm{ij}} X_{\mathrm{ij}}+\in_{\mathrm{ij} .}$. Conclui-se que os metais pesados Cd e Cr têm uma velocidade instantânea igual, ou seja, os mesmos têm fluxo semelhante na água subterrânea. E os metais $\mathrm{Pb}$ e Ni têm um comportamento, na cinética do efluente líquido, distinto dos demais. E o $\mathrm{Zn}$ se comporta completamente diferente de todos os outros metais determinados.

Os metais pesados $\mathrm{Cd}$ e $\mathrm{Pb}$ determinados nas amostras do piezômetro estão em desacordo com os valores permissíveis pela Portaria 36/90 do Ministério da Saúde, que estabelece o padrão de potabilidade da água destinada ao consumo humano. Conclui-se que estes metais indicam contaminação das águas subterrâneas provenientes do Aqüífero Botucatu.

Os metais pesados $\mathrm{Cd}, \mathrm{Pb}$, e $\mathrm{Cr}$ determinados na solução do solo do extrator estão em desacordo com o padrão de potabilidade da água destinada ao consumo humano estabelecido pela Portaria 36/90 do MS. Concluí-se que estes metais pesados indicam contaminação do solo.

As concentrações dos metais pesados na solução do solo são maiores do que na água subterrânea. Conclui-se que o poder atenuador de poluição do solo foi comprovado, pois quando a água contaminada entra no solo ou aqüífero, a con- 
centração dos poluentes decresce com o aumento da distância do fluxo.

Os metais pesados $\mathrm{Cd}, \mathrm{Pb}, \mathrm{Cr}$, Ni e Zn determinados no efluente superficial (chorume) na base do aterro e na lagoa de acumulação estão de acordo com os valores permissíveis para efluentes a serem lançados nos corpos d'água, conforme Resolução CONAMA 20/86. Isto pode ser atribuído ao processo de diluição pela chuva. Entretanto, conclui-se que o efluente líquido na base do aterro tem uma carga poluidora, referente aos metais pesados, maior que a lagoa de acumulação.

As concentrações do metal pesadas Ni na água superficial na nascente estão em desacordo com o valor permissível pela Resolução CONAMA 20/86, para classes (classe I) de água doce. Conclui-se que a concentração deste metal indica contaminação da água superficial.

Os valores de $\mathrm{pH}$ estão de acordo com os valores máximos permissíveis pela Resolução CONAMA 20/86 e pela Portaria MS 36/90, em todos os pontos de amostragem. Concluí-se que o $\mathrm{pH}$ do efluente superficial (chorume) é alcalino, e o $\mathrm{pH}$ do efluente (percolado/lixiviado) é ácido tendendo ao tamponamento, devido ao mecanismo de atenuação de poluição do solo.

Os valores máximos permissíveis de DQO não constam na Resolução CONAMA 20/86 e nem na Portaria MS 36/90. Concluí-se que as concentrações baixas de DQO podem ser atribuídas aos mecanismos de diluição pela chuva. Concluí-se, também, que os impactos ambientais provenientes dos metais pesados são mais preocupantes do que as excessivas cargas orgânicas degradáveis.

O local do aterro é formado por solo de textura média, com teores de $65 \%$ de areia e $27 \%$ de argila. Concluí-se que existe uma influência da lixiviação nos parâmetros determinados, devido ao alto teor de areia. Conclui-se, também, que os resultados obtidos dos parâmetros indi- cadores de poluição, em desacordo com a legislação consultada, podem ser atribuídos a falta de uma impermeabilização inferior adequada do aterro. Lembrando que a região de Botucatu é uma área de recarga do Aquiífero Botucatu e o Município possui $26 \%$ de sua área inserida dentro dos limites de uma área proteção ambiental (APA), portanto as proteçōes ambientais devem ser redobradas.

As variações de composição do efluente líquido em um aterro sanitário são bem complexas. Portanto, é difícil a comparação entre pesquisas, pois a literatura nem sempre fornece dados completos para uma avaliação padrão de parâmetros determinados no efluente liquido.

\section{AGRADECIMENTO}

A autora agradece a CAPES - Fundação Coordenação de Aperfeiçoamento de Pessoal de Nível Superior, pela bolsa de Doutorado cedida à mesma.

\section{REFERÊNCIAS}

CASTILHOS JR., A.B. Estimativa da distribuição e dos teores dos metais pesados nas diversas fraçōes dos resíduos urbanos no Brasil. BIO - Rev. Bras. de San. e Meio Amb., p.57-60, 1989.

CETESB. Companhia de Tecnologia de Saneamento Ambiental. Guia de coleta e preservação de amostras de água. São Paulo. CETESB, 150p. 1987.

DAMASCENO, S. Remoção de metais pesados em sistemas de tratamento de esgoto sanitário por processo de lodo ativado e por um reator compartimentado anaeróbio. 1996. 141p. Dissertação (Mestrado em Hidráulica e Saneamento) - Escola de Engenharia de São Carlos, Universidade de São Paulo, São Carlos, 1996.

EMBRAPA-Empresa Brasileira de Pesquisa Agropecuária. Critérios para distinção de classes de solos e de fases de unidades de mapeamento em uso pelo Serviço Nacional de Levantamento e Conservação de Solos. Rio de Janeiro. EMBRAPA, 67p. 1988.

IG-Instituto Geológico do Estado de São Paulo. Mapeamento da vulnerabilidade e risco da poluição das águas subterrâneas no Estado de São Paulo. São Paulo. IG, 129p. 1997.
IPT-Instituto de Pesquisas Tecnológicas do Estado de São Paulo. Lixo municipal: manual de gerenciamento integrado. 2.ed. São Paulo. IPT/CEMPRE, 370p. 2000

OLIVEIRA, S. et al. Caracterização física dos resíduos sólidos domésticos (RSD) da cidade de Botucatu/SP. Eng. Sanit. e Amb., v.4, n.3, p.113-16, 1999 .

ORTH, M.H. de A., Di CREDDO, E.B. $A$ recuperação ambiental do lixão de Carapicuíba. Rev. Limp. Públ., n.52, p.05-15, 1999.

ROCCA, A.C.C. et al. Residuos sólidos industriais. 2.ed. São Paulo. CETESB, 234p. 1993.

ROLIM, G. de S., et. al. Planilha no ambiente excel ${ }^{T M}$ para os cálculos de balanços hídricos: nor mal, seqüencial, de cultura e de produtividade real e potencial. Rev. Bras. de Agromet., v.6, n.1, p.133-37, 1998.

SANTOS, P.C.V. Estudo da contaminação de água subterrânea por percolado de aterro de resíduos sólidos - Caso Jockey Club - DF Brasília, 135p. Dissertação (Mestrado em Geotecnia) Faculdade de Tecnologia, Universidade de Brasília. 1996

SARUBBI, A. Lixiviação en rellenos sanitarios. Rev. Interamer. Amb. y Saneam., n.3, p.0411, 1998.

SCHALCH, V. Produção e características do chorume em processo de decomposiçāo de lixo urbano. 103p. Dissertação (Mestrado em Hidráulica e Saneamento) Escola de Engenharia de São Carlos, Universidade de São Paulo, São Carlos, 1984

STANDARD METHODS for the examination of water and wastewater. Preparado e publicado por APWA/AWWA/WEF. 18 ed. Washington: American Public Health Association, 126p. 1992

Endereço para correspondência:

Selene de Oliveira

UNESP/FCA - Botucatu/SP

Rua Antonio Gabriel, 48 - C

I 8606- I 70 - Botucatu - SP - Brasil

Tel.: (I4) 38 I4- I I97

E-mail: selene2002br@yahoo.com.br

\title{
engenharia sanitória e ambiental
}

Indexação: Repidisca - Rede Panamericana de Informaciones en Salud Ambiental

\author{
Editoria Científica Nacional \\ esa@abes-dn.org.br - abes@abes-dn.org.br
}

